\title{
Teaching Computer Networks: Theory and Problem Solving
}

\author{
Atila Bostan
}

\begin{abstract}
Teaching data communication and networks is one of the challenging tasks in information systems education. It should include a good deal of theoretical and practical education mutually. Students frequently encounter with new applications and networking problems in their ever day practices. Introducing network diagnostic tools and experiencing problem solving in computer networks should be significant components of network education. In this study we have presented the results of an educational methodology change in teaching data communication and networks course. Students are forced to solve more problems and have more hands on practices. The findings point to a better educational achievement when compared with the previous teaching methodology.
\end{abstract}

Index Terms-Data communication and network education, educational methodology, problem-based learning.

\section{INTRODUCTION}

Teaching and learning are still phenomenon on which educational and cognitive scientists have ongoing researches. Teaching process, with a high level of abstraction, is defined as "to cause or help (a person or animal) to learn how to do something by giving lessons and showing how it is done", whereas learning is referred as "to gain knowledge or skill by studying, practicing, being taught, or experiencing something" [1]. With these definitions, one can easily deduce that the essential components of teaching and learning processes are; having lessons, studying, practicing and gaining experience. Moreover, these components may be classified as theoretical and practical groups, such that having lessons and studying fall in to theoretical group and practicing and gaining experience fall in to practical group. Educational and applicative requirements for these two component classes are quite different than the other. Theoretical group call for logical and procedural understanding while practical group requires experimenting and hands-on implementations. Therefore practical group generally necessitates a special learning environment, such as a laboratory, and particularly engineered experimental problems. Additionally practicing and gaining experience require reasonably more time than theoretical studying and tools to be acquired. Hence, in most of the learning environments in the universities, theoretical teaching is preferred as educational methodology (curriculum, course contents and educational environment), neglecting the noteworthy component of learning; that is to gain experience.

On the other hand, in order to enhance logical

Manuscript received June 26, 2015; revised December 12, 2015

Atila Bostan is with the Computer Engineering Department, Atılım University, Kizilcasar Mah. Incek-Golbasi, Ankara, Turkey (e-mail: atila.bostan@atilim.edu.tr). understanding, to facilitate gaining real life practices and to measure educational achievements adequately, problem solving approach can be used in educational settings as well [2]. Problem solving entails significant amount of theoretical knowledge and experience collectively. It intrinsically includes the design of a solution path which is composed of measurement, calculation, detection and management tool usages. Therefore, considerable amount of experience is essential for a good problem solving skill.

Computer networks are almost inevitable infrastructure in today's business and social transactions. Moreover, their technology is rapidly changing and new applications, new protocols are introduced in short intervals. Preparing the computer, software and information systems engineering students for real-life network problems is a challenging task [3]. Besides the theoretical education, teaching the technology used in computer networks should include a good amount of practical case studies [4]. Students should better be ready to solve real life network problems when they graduate.

In this study we have presented the results of an educational methodology change in teaching data communication and networks course. Students are forced to solve more theoretical problems and have more hands on practices. The findings point to a better educational achievement when compared with the previous teaching methodology.

\section{RESEARCH METHODOLOGY AND HYPOTHESES}

Teaching the fundamentals of data communication and computer networks is a challenging task, since it relies on a versatile infrastructure and there are quite amount of real-life applications used in daily routines [5]. Moreover, the excessive number of terms and locutions in the domain, and sometimes their misusage, do not help in describing the technological details. On the other hand special educational methodologies yield better results in different education realms. An educational methodology may result superior consequences in teaching a specific course, whereas it fails in that of the other course [6]. Thus finding the best educational methodology for a definite course is a special problem which needs to be scrutinized in the context of present and particular educational settings. The order of course in the current curriculum, course prerequisites, instructor's conducts, student's readiness and alacrity have impact on the success of the educational methodology in the course as well, while the course content deserves to be the most important factor in choosing the methodology [7].

In this study we reported the outcomes of a methodology change in data communication and computer networks 
education through a comparison with the previous application. The research model was developed to find an answer to the following main question.

Does the proposed educational methodology (see Section III.B) have positive impact on teaching the data communication and computer networks course?

For this purpose we have elaborated following sub-hypothesis. By the virtue of these sub-hypotheses we examined the answer to the main question in the study.

\section{Hyp. Definition}

H1: Conducting in-class quizzes increase student success more than that of homework assignments.

$\mathrm{H} 2$ : Hands-on examination on network diagnostic tool usage and network application development provides better educational measurement framework for individual evaluations.

\section{RESEARCH DESIGN}

\section{A. Data Collection}

Data used in this study were collected in Data Communications and Networks course which was given in At1lim University engineering faculty for computer engineering, software engineering and information systems engineering students as a must course. Data covers five semesters with a total of 532 students. The course is offered in spring semesters in each educational calendar. The course is offered in multiple sections with around 30 students in each in maximum. Hence total number of sections differs depending on the total number of students who has registered to the course. The semesters scrutinized in this study are the spring terms of 2009-2010, 2010-2011, 2011-2012, 2012-2013 and 2013-2014 educational years. Student grades in the midterm-I, midterm-II and final examinations are used as dependent variables. Data set is divided into two groups where 2009-2010 and 2010-2011 spring semesters fall in to the previous educational methodology group and 2011-2012, 2012-2013 and 2013-2014 fall in to the new educational methodology group. The former data group is named as homework-project, while the latter group is named as problem-solving, in order to represent the educational methodology change between the groups. Details of the change in educational methodology are reported in the following section.

\section{B. Change in Educational Methodology}

Data Communication and Networks course is offered as a joint-departmental must course for computer, software and information systems engineering students in At1lim University engineering faculty. The course was directed in multiple sections with a different instructor in each section. Students are to attend three hours of lecture and two hours of laboratory studies in a week. Lectures focus on the theory and applied protocols, whereas the laboratory studies aims to learn how to use basic networking and diagnostic tools and gain experience on network-applications. Additionally fundamental principles of socket programming and network-application development is thought in laboratory studies, as well. In 2009-2010 and 2010-2011 academic years, the students were to submit three homework individually through the semester and develop a network-project in a group of four members in maximum. Homework were designed to force the students to study the topics which were not covered in the lectures and solve network-problems which need more time to find the correct answer. On the other hand, in group projects students were required to develop a simple network-application in order to deepen their understanding and widen their experience in the domain. Unfortunately, instructors who had given this course were not happy with both homework and project practices. Since, it was hard to discriminate a copy in the homework and to evaluate individual contributions in the projects. Furthermore, the instructors claimed that significant number of students had outsourced their study. Hence, evaluation of the student studies were unfair.

Discontent of the instructors in student homework and project studies, directed us to develop alternative measures and applications in education methodology in data communication and networks course. In order to replace homework and project assignments, it is decided to administer in-class quizzes, hands-on problem solving and application development practices. In-class quizzes consist of two or three questions and are conducted in 15 or 20 minutes. However, prior to the quizzes, about one week before the quiz administration, a sample question set is announced with a notice indicating that the questions in the quizzes will be the same or similar to the sample questions. Hands-on examination is held at the end of the semester with the intention to evaluate student achievements in basic network-diagnostic tool usage and socket programming.

\section{Data Analysis}

Hypothesis 1 was tested using independent samples t-test. Statistical inference techniques are well known and appear in many of the standard text books on probability and statistics (see for example [8]-[10]). Statistical hypothesis testing method t-test can be used to determine if two data sets are significantly different from each other or not [11]. T-test is a powerful statistical tool and is used in wide variety of applications [12]. The significance level of the difference between two sample groups is reported with sigma coefficient in t-test. If sigma coefficient is less than 5\% then the difference between the groups is referred to be significant otherwise observed difference is statistically insignificant [12]. We used independent samples t-test, since we examined examination grades of different student groups in this study.

In examination of hypothesis 2 we used chi-square testing. Chi-square test uses the variation of the data sets to decide on whether the two sets are statistically different or not. In other words it is a measure to quantify the amount of variation in a data set. We have used chi-square test in comparing student examination grades in project-development and hands-on examination.

Student examination papers evaluated out of 100 points. But the questions asked and the distribution of the marks in an examination was inevitably different than that of the other semester. Although the instructors tried to keep the equity between semesters in preparing the questions, the discrepancies were unavoidable. Therefore we normalized student examination grades in order to have a sound comparison between the semesters. In the normalization of grades we used following formula: 


$$
\mathrm{Nsg}=\frac{\mathrm{Sg}-\min \_\mathrm{g}}{\max \_g-\min \_g} \times 100
$$

where;

Nsg : Normalized student grade

$\mathrm{Sg} \quad$ : Student grade

min_g : minimum grade in the examination

max_g : maximum grade in the examination

\section{RESULTS}

The results of the study are presented in the following sequence. Initially a descriptive analysis is presented with the number of students and average examination grades in each semester.

\section{A. Descriptive Results}

The number of students along with normalized examination grade averages for each semester is listed in Table I. A total of 529 student grades are covered in this study. There are 245 students in homework-project group and there are 284 students in problem-solving group. There was no hands-on examination in 2009-2010 and 2010-2011 semesters, while students were exempt from project development in rest of the semesters.

\begin{tabular}{|c|c|c|c|c|c|c|c|}
\hline \multirow[b]{2}{*}{ 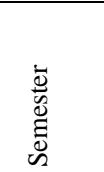 } & \multirow[b]{2}{*}{ 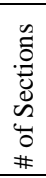 } & \multirow[b]{2}{*}{ 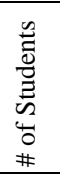 } & \multicolumn{5}{|c|}{ Normalized Grade Average } \\
\hline & & & $\stackrel{?}{\stackrel{7}{2}}$ & $\frac{\overline{1}}{D^{\prime}}$ & 茎 & $\begin{array}{l}\frac{\vec{U}}{0} \\
\frac{\dot{D}}{2}\end{array}$ & 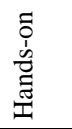 \\
\hline 2009-10 & 4 & 128 & 57.65 & 48.43 & 53.42 & 49.03 & - \\
\hline $2010-11$ & 4 & 117 & 55.05 & 52.27 & 51.98 & 47.19 & - \\
\hline 2011-12 & 3 & 92 & 64.16 & 59.83 & 60.49 & - & 63.78 \\
\hline $2012-13$ & 3 & 86 & 68.72 & 73.54 & 62.13 & - & 59.67 \\
\hline 2013-14 & 4 & 106 & 66.31 & 69.92 & 61.96 & - & 67.14 \\
\hline
\end{tabular}

\section{B. Test Results}

In order to test hypothesis $\mathrm{H} 1$, it is required to investigate three special relationships since each examination should be tested particularly between the two application groups. Three relationships which were investigated are listed below with a subscript notation of hypothesis $\mathrm{H} 1$.

- $\mathrm{H}_{1}$ : There is difference between two application groups in first midterm examination grades

- $\mathrm{H}_{2}$ : There is difference between two application groups in second midterm examination grades

- $\mathrm{H}_{3}$ : There is difference between two application groups in final examination grades

Independent samples t-test result for $\mathrm{H} 1_{1}$ is shown in Table II.

With the interpretation of the test results for $\mathrm{H} 1_{1}$, the difference between homework-project $(M=56.9, S D=17.4)$ and problem-solving $(M=66.1, S D=13.9)$ groups on the first midterm examination grades is statistically significant $(t(527)=2.815, p=0.019)$. Therefore, the premise $\mathrm{H} 1_{1}$ is accepted. In other words, with regard to first midterm examination grades there is significant difference between homework-project and problem solving groups.

Independent samples t-test result for $\mathrm{H}_{2}$ is shown in Table III.
TABLE II: INDEPENDENT SAMPLES T-TEST RESULTS FOR H $1_{1}$

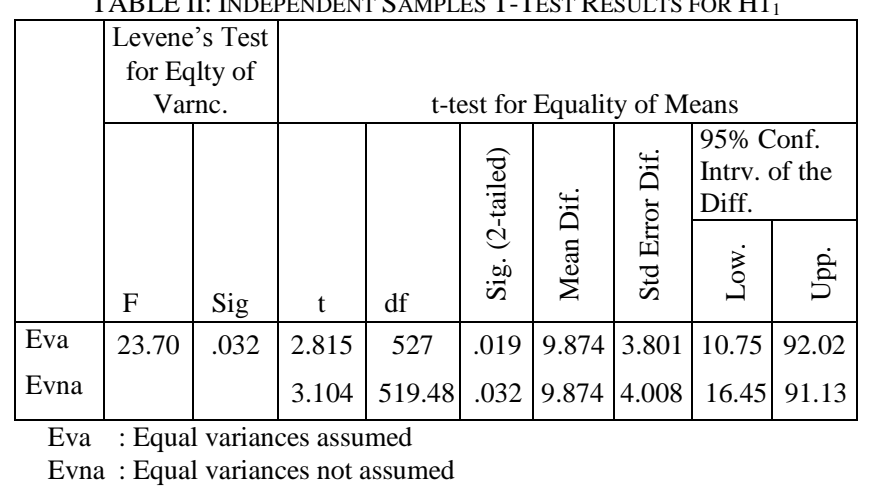

TABLE III: INDEPENDENT SAMPLES T-TEST RESULTS FOR H1

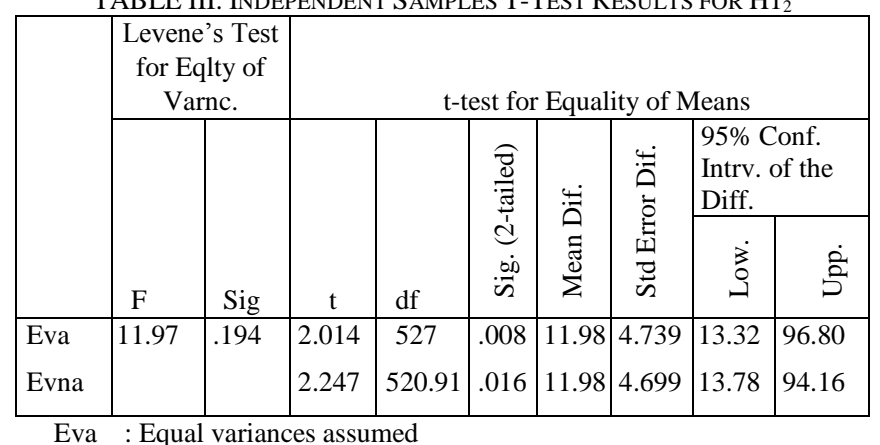

Evna : Equal variances not assumed

Test results for $\mathrm{H} 1_{2}$ indicates that, the difference between homework-project $(M=50.2, S D=21.7)$ and problem-solving $(M=68.4, \quad S D=19.3)$ groups on the second midterm examination grades is statistically significant $(t(527)=2.014$, $p=0.008$ ). Therefore, the premise $\mathrm{H}_{2}$ is accepted. This means, the difference between homework-project and problem solving groups in second midterm examination grades is statistically significant as well

The test result on final examination grades between application groups $\left(\mathrm{H}_{3}\right)$ is shown in Table IV.

TABLE IV: INDEPENDENT SAMPLES T-TEST RESULTS FOR $\mathrm{H}_{1}$

\begin{tabular}{|c|c|c|c|c|c|c|c|c|c|}
\hline & \multicolumn{2}{|c|}{$\begin{array}{c}\text { Levene's Test } \\
\text { for Eqlty of } \\
\text { Varnc. }\end{array}$} & \multicolumn{7}{|c|}{ t-test for Equality of Means } \\
\hline & \multirow[b]{2}{*}{$\mathrm{F}$} & \multirow[b]{2}{*}{ Sig } & \multirow[b]{2}{*}{$\mathrm{t}$} & \multirow[b]{2}{*}{ df } & \multirow{2}{*}{ 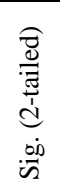 } & \multirow{2}{*}{ 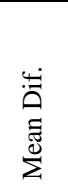 } & \multirow{2}{*}{ 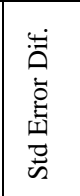 } & \multicolumn{2}{|c|}{$\begin{array}{l}95 \% \text { Conf. } \\
\text { Intrv. of the } \\
\text { Diff. }\end{array}$} \\
\hline & & & & & & & & 3 & $\stackrel{\dot{2}}{\Omega}$ \\
\hline Eva & 19.29 & .262 & 2.476 & 527 & .036 & 12.52 & 5.140 & 18.35 & 87.48 \\
\hline Evna & & & 2.408 & 521.17 & .042 & 12.52 & 5.106 & 17.04 & 91.10 \\
\hline
\end{tabular}

Table IV demonstrated that, the difference between homework-project $(M=52.3, S D=19.4)$ and problem-solving $(M=61.8, \quad S D=13.7)$ groups on the second midterm examination grades is statistically significant $(t(527)=2.476$, $p=0.036$ ). Therefore, the premise $\mathrm{H}_{3}$ is accepted. With this result, it is safe to say, the difference between homework-project and problem solving groups in final examination grades is significant.

Seeing that all three premises $\left(\mathrm{H}_{1}, \mathrm{H}_{2}\right.$, and $\left.\mathrm{H}_{3}\right)$ are all statistically accepted, we can directly deduce that $\mathrm{H} 1$ is accepted. This simply means, problem-solving group was 
more successful in Data Communication and Networks course examinations than that of project-homework group. Therefore, these results may be a strong indicator for conducting in-class quizzes increase student success more than that of homework assignments (hypothesis H1).

In examining the hypothesis $\mathrm{H} 2$, chi-square test resulted with $\mathrm{X} 2(1)=16.47, p=0.023$ values. Test results point out that the distribution of project grades and hands-on examination grades are considerably different than each other Moreover the grade frequency distribution analysis shows 8 distinct grades in project evaluations and 22 distinct grades in hands-on examination grades were used. In Fig. 1, the distribution graphs of grades for two different application groups are shown.

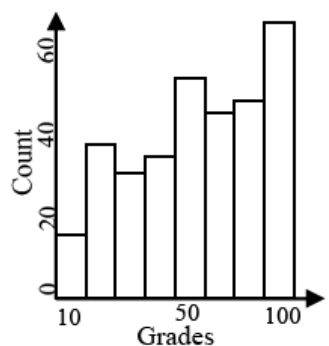

(a)

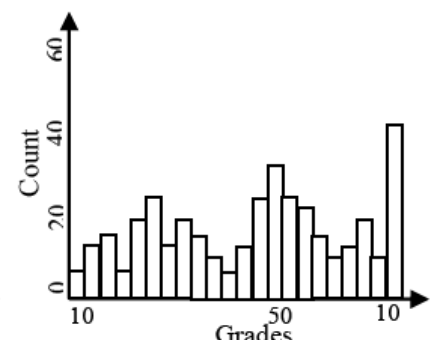

(b)
Fig. 1. Grade distribution in (a) project group (b) hands-on examination.

\section{CONCLUSION}

Teaching data communication and networks is one of the challenging tasks in information systems education. It should include a good deal of theoretical and practical education mutually. Data communication is almost inevitable technology used in daily routines. Therefore students frequently encounter with new applications and networking problems in their ever day practices. Introducing network diagnostic tools and experiencing on problem solving in computer networks should be significant components of network education. In this study we have scrutinized the effect of educational methodology in learning the data communication and networks with an educational practice in Atılım University.

The results of the study indicate that when students have sample questions in hand to study they are prone to get higher grades in the examinations. However student's perception of the necessity to study on the sample questions should not be underestimated. We believe that having in-class quizzes enhance student's need to study the sample question set. On the other hand, conducting a hands-on application examination on the practice of network diagnostic tools and network programming compels the students to have more experience on them. Moreover some of the students expressed that they found this practice useful in understanding and sometimes in solving network problems in their daily routines.

In conclusion the findings in this study suggest that, by the acceptance of hypothesis $\mathrm{H} 1$, conducting in-class quizzes increase student success more than that of homework assignments. Furthermore, evidences in this study show that hand-on practical examination provide better individual educational assessment than that of group project studies. With these results we can simply state in-class quizzes with preceding sample question set and hands-on example on network diagnostic tools and network programming increase student enhancements in data communication and network course.

These results may be specific to data communication and networks topic. Since not all the courses have enough practical tools for students to practice or diagnose. But, at least for data communication and network course the suggested educational methodology provides better results when compared with homework assignment and project development application. We strongly recommend data communication and network course instructors to use sample questions and to inspire students to have hands-on experiments as much as possible for a successful data communication and network instruction.

\section{REFERENCES}

[1] K. Tyner, Literacy in a Digital World: Teaching and Learning in the Age of Information, Routledge, 2014.

[2] K. Anette and E. de Graaff, "Problem-based and project-based learning in engineering education," Handbook of Engineering Education Research, pp. 141-160, 2014

[3] R. C. Davis, "Teaching the network: A brief demonstration of the internet's structure for information literacy instruction," Behavioral \& Social Sciences Librarian, vol. 34, issue 2, pp. 88-94, 2015.

[4] Y. D. Ren, "The application of multimedia and modern network for college sports curriculum teaching," in Proc. 2014 IEEE Workshop on Advanced Research and Technology in Industry Applications, 2014, pp. $651-653$

[5] W. J. Jiao and X. W. Hao, "Design of a web-based computer network experiment teaching demonstration system," International Journal of Information Technology and Management, vol. 13, no. 1, pp. 44-53, 2014.

[6] T. R. Murray and V. N. Kobayashi, Educational Technology - Its Creation, Development and Cross-Cultural Transfer, Elsevier, 2014.

[7] B. D. Nye, "Intelligent tutoring systems by and for the developing world: a review of trends and approaches for educational technology in a global context," International Journal of Artificial Intelligence in Education, vol. 25, no. 2, pp. 177-203, 2014.

[8] W. Mendelhal and T. Sincich, Statistics for the Engineering and Computer Sciences, Maxwell McMillan International Editions, 1989.

[9] I. Miller and J. E. Freund, Probability and Statistics for Engineers, Prentice-Hall, 1985.

[10] J. S. Milton and L. C. Arnold, Introduction to Probability and Statistics: Principles and Applications for Engineering and the Computing Sciences, $4^{\text {th }}$ ed. Boston, MA: McGraw Hill, 2002.

[11] B. C. Gupta and I. Guttman, Statistics and Probability with Applications for Engineers and Scientists, John Wiley \& Sons, 2014.

[12] S. M. Ross, Introduction to Probability and Statistics for Engineers and Scientists, Academic Press, 2014.

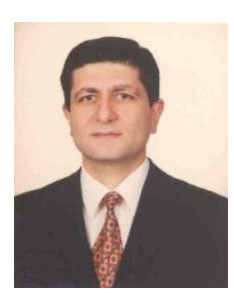

Atila Bostan received his B.Sc. degree in 1986 and completed his M.Sc. degree in 1997 at Middle East Technical University on Computer Engineering. He finished his Ph.D. studies in Gazi University in 2007. Atila Bostan has worked as a system operator, system planner and project officer in military organizations. He has participated in several NATO projects as well. Atila Bostan is holding several certificates, awards and honors especially in the field of computer security. Following his retirement from government, he attended to Atılım University, Computer Engineering Department as an assistant professor. Atila Bostan is giving courses on computer networks, network and system security. His research and interest areas include computer networks, security and image processing. 
Network Security and Technology 
